Revista de
Economild
Contemporâned

\title{
AMÉRICA LATINA NO SÉCULO XXI E A REESTRUTURAÇÃO PRODUTIVA À LUZ DA TEORIA DA CEPAL
}

\author{
Ana Maria Rita Milani ${ }^{a}$ \\ Vitor Emanuel Feitosa Hortencio ${ }^{b}$
}

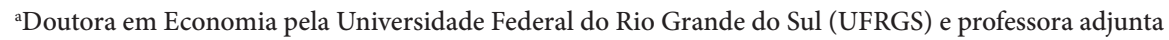
da Faculdade de Economia, Administração e Contabilidade da Universidade Federal de Alagoas (UFAL).

Maceió, Alagoas, Brasil. ORCID: https://orcid.org/0000-0002-2842-381X.

${ }^{b}$ Mestre em economia pela UFAL. Estudante de Doutorado do Programa de Pós-Graduação em Economia da Universidade Federal da Bahia (UFBA). Salvador, Bahia, Brasil.

ORCID: https://orcid.org/0000-0002-9553-398X.

\section{Recebido em 15 de fevereiro de 2019 \\ Aceito em 18 de julho de 2019}

RESUMO: Ao longo dos 70 anos de existência da CEPAL o pensamento que inspira seus principais trabalhos esteve guiado pelo método histórico estrutural e a perspectiva do sistema centro-periferia, a qual salienta que as possibilidades de desenvolvimento da região "periférica" estariam condicionadas pelos movimentos da economia mundial. Na década de 1990, os países da região aderem aos modelos de ajuste estrutural, concretizando o triunfo do neoliberalismo. Diante desse contexto, o debate sobre a necessidade da industrialização regional ainda segue vivo, alimentado, de um lado, pelo desempenho industrial medíocre da região latino-americana e, por outro, pelo fato de a região ter sido beneficiada pela favorável conjuntura internacional na primeira década do século XXI, mas com a ampliação dos setores produtores de commodities. Assim, este artigo tem como objetivo analisar a reestruturação estrutural no começo do século XXI em América Latina, tendo como base teórica as contribuições 
da CEPAL, para entender com se apresenta a mudança estrutural nas economias da região. Observou-se que a mudança estrutural na América Latina no século XXI aconteceu de forma complexa, e sua compreensão requer a análise de muitas variáveis que entrariam na construção do caminho para o desenvolvimento na visão da CEPAL.

PALAVRAS-CHAVE: América Latina; CEPAL; mudança estrutural.

CLASSIFICAÇÃO JEL: O1. 


\title{
LATIN AMERICA IN THE 21ST CENTURY AND PRODUCTIVE RESTRUCTURING IN THE LIGHT OF THE ECLAC THEORY
}

\begin{abstract}
Throughout the 70 years of ECLAC's existence, the thinking that inspired its main works have been based on the structural historical method and the center-periphery model, according to which the movements of the world's economy would determine the development of the "peripheral" regions. In the 1990s, the countries in Latin America adhered to the structural adjustment models, bringing about the triumph of neoliberalism. As the economies in the region experienced mediocre industrial performance in the following decade but benefited from the favorable international economic environment of the 2000s, with the expansion of commodity sectors, the debate on the need for regional industrialization in the region is still alive. Thus, this article aims to analyze the structural change in Latin America economies at the beginning of the 21st century, based on ECLAC's contributions. The analysis suggests that the restructuring of Latin American economies has happened in a much complex way and that the understanding of such a process involves the analysis of many variables embodied in ECLAC's vision of development.
\end{abstract}

KEYWORDS: Latin America; ECLAC; structural change. 


\section{INTRODUÇÃO}

As teorias cepalinas, propagadas a partir dos anos 1950, sustentavam que a única forma de a América Latina poder transitar da periferia ao centro do sistema internacional era por meio do processo de industrialização, rompendo assim a lógica das economias primário-exportadoras. Espera-se que essa questão já tivesse sido resolvida depois de mais de meio século da publicação do texto "O desenvolvimento econômico da América Latina e alguns de seus principais problemas”, escrito por Raúl Prebisch (2000a[1949]).

Ao longo dos 70 anos de existência da Comissão Econômica para a América Latina (CEPAL), o pensamento que inspirou os principais trabalhos da instituição baseou-se no método histórico estrutural e na perspectiva do sistema centro-periferia, a qual salienta que as possibilidades de desenvolvimento da região "periférica" estariam condicionadas pelos movimentos da economia mundial. A instituição teve uma inegável contribuição teórica para a compreensão da problemática latino-americana, caracterizando a região como subdesenvolvida. Seguindo a interpretação estruturalista cepalina, o subdesenvolvimento da região apresenta três caraterísticas básicas: (i) escassa ou inadequada diversificação da produção e das exportações; (ii) heterogeneidade estrutural; e (iii) pouca eficácia das instituições para alavancar as estratégias do desenvolvimento. Desde suas origens até a atualidade, esses temas se transformaram na marca registrada da instituição.

No entanto, na década de 1990 as ideias neoliberais se concretizaram através do Consenso de Washington, com base na implementação do receituário que recomendava a liberalização comercial e financeira, a desregulamentação e a globalização dos mercados. Os países da região aderiram aos modelos de ajuste estrutural, concretizando o triunfo do neoliberalismo.

A história recente mostra que a primeira década do século XXI foi marcada por importantes transformações no sistema econômico internacional. O desenvolvimento econômico recente da China desencadeou uma nova dinâmica no comércio mundial, com a crescente demanda daquele país por matérias-primas, a internacionalização das empresas chinesas e sua adesão à Organização Mundial do Comércio (OMC) em 2001. A conjuntura internacional favorável trouxe um período de bonança para as economias latino-americanas, caracterizado por uma melhora nas taxas de crescimento, emprego e pobreza a partir dos anos 2002. Além disso, a América Latina vem se especializando gradativamente na produção de commodities minerais e alimentares. Por conseguinte, a ascensão econômica encabeçada pela China reestrutura a divisão internacional do trabalho provocando dois efeitos comerciais na região: (i) um efeito positivo no balanço de pagamentos devido ao aumento da demanda desse país e (ii) uma 
especialização que pode ser classificada como regressiva, pois se especializa em commodities.

Diante desse contexto, o debate sobre a necessidade da industrialização regional ainda segue vivo, alimentado, de um lado, pelo desempenho industrial medíocre da região latino-americana e, por outro, pelo fato de ter sido beneficiada pela favorável conjuntura internacional na primeira década do século XXI, mas com a ampliação dos setores produtores de commodities. Com vistas a contribuir para esse debate, o presente artigo se propõe a analisar a reestruturação produtiva na América Latina no começo do século XXI, tendo como base teórica as contribuições da CEPAL, para entender com se apresenta a mudança estrutural nas economias da região.

A metodologia utilizada neste artigo compreendeu uma revisão teórica e bibliográfica de caráter qualitativo que pretende entender os fenômenos socioeconômicos de forma interpretativa a partir dos autores cepalinos. $\mathrm{O}$ arcabouço teórico escolhido para atingir o objetivo analítico proposto foi baseado nos seguintes autores: a partir das primeiras contribuições da CEPAL, no período seminal, os trabalhos de Raúl Prebisch, Celso Furtado e Aníbal Pinto são tomados como ponto de partida. Dessa forma, serão apresentados os conceitos que ajudaram na interpretação da problemática latino-americana e são os seguintes: subdesenvolvimento, centro-periferia, heterogeneidade estrutural, modernização e dependência.

Além desta introdução, a primeira seção abordará as contribuições teóricas da CEPAL com foco nos temas centrais do desenvolvimento da região, especialmente aquelas dos primórdios da instituição, como, por exemplo, heterogeneidade estrutural, centro-periferia, industrialização, etc. Na segunda seção, abordar-se-á a caraterização da reestruturação produtiva na América Latina, fazendo uma contextualização por meio de fatos estilizados para logo adentrar na caracterização da mudança estrutural. Por fim, apresentam-se as considerações finais.

\section{A CEPAL: A ORIGEM E AS CONTRIBUIÇÕES DO PENSAMENTO CEPALINO}

A CEPAL foi constituída em 1948, por decisão da Assembleia Geral das Nações Unidas de 1947. A instituição é uma das cinco comissões regionais das Nações Unidas ${ }^{1}$ e sua sede está localizada em Santiago do Chile. Foi fundada com o objetivo de fazer um

\footnotetext{
As cinco comissões regionais são: A Comissão Econômica para a África, a Comissão Econômica para a América Latina e Caribe, a Comissão Econômica para a Europa, a Comissão Econômica e Social para a Ásia e o Pacífico e a Comissão Econômica e Social para a Ásia Ocidental (ONU, 2016).
} 
diagnóstico da condição de atraso econômico da região, propondo alternativas direcionadas à promoção do desenvolvimento reforçando as relações econômicas. Para Bielschowsky (2000, p. 20) "a CEPAL desenvolveu-se como uma escola de pensamento especializada no exame das tendências econômicas e sociais de médio e longo prazos dos países latino-americanos".

A CEPAL foi a principal fonte de informações e análise sobre a realidade econômica e social latino-americana. Seu princípio "normativo" é a ideia da necessidade da contribuição do Estado ao ordenamento do desenvolvimento econômico nas condições da periferia latino-americana (BIELSCHOWSKY, 2000). Mesmo com uma diversidade de conceitos e maneiras de formular a questão do subdesenvolvimento, todo o arcabouço cepalino convergia para a mensagem central de que é necessário realizar políticas de industrialização como forma de superar o subdesenvolvimento e a pobreza. Segundo Bielschowsky (2000, p. 24),

Havia, para os defensores da industrialização, uma espécie de "vazio teórico", e a descrença em relação à teoria econômica existente gerava perplexidade face à falta de teorias que pudessem ser adaptadas às realidades econômicas e sociais que se tentava entender e transformar.

A instituição adopta como método o histórico-estrutural, o qual é essencialmente um enfoque orientado pela busca de relações diacrônicas, históricas e comparativas, que se relaciona mais ao método "indutivo" do que a uma "heurística positiva” (BIELSCHOWSKY, 2000). Assim, criou-se um corpo analítico específico aplicado às condições peculiares e próprias da periferia latino-americana, estudando-se de forma esquemática a relação da região como o resto do mundo. Para os pensadores da CEPAL a forma de inserção internacional é de fundamental importância para entender o subdesenvolvimento. Nesse sentido, surge a categoria de análise centro-periferia, ${ }^{2}$ que salienta a relevância que cada país tem na divisão internacional do trabalho. Segundo Prebisch, a violenta contração da capacidade para importar vista nos anos 1930 e seus reflexos nas economias latino-americanas constituíram a referência histórica da vulnerabilidade externa, a qual evidenciava o modo de funcionamento das economias industrializadas e aquelas fundamentadas no modelo primário-exportador (BIELSCHOWSKY, 2000).

Para o estruturalismo cepalino, é necessária adotar uma visão global da expansão do sistema capitalista para elucidar as diferentes estruturas criadas, as quais confor-

2 Prebisch já utilizava a expressão “países periféricos” bem antes de ingressar na CEPAL. 
mam uma relação de autonomia e dependência. Entende-se, então, que o estudo dos centros e das periferias se inicia com a propagação do progresso técnico na economia mundial e termina com a análise do comportamento das economias recebedoras dessas tecnologias, condicionando uma simbiose de poder e dependência. O esforço de propagação das técnicas a partir das regiões centrais tinha o objetivo de superar os obstáculos físicos e econômicos que pressionavam a redução da eficácia do processo acumulativo. Por seu turno, o núcleo industrial buscava ampliar sua zona de ação criando uma constelação de economias dependentes (FURTADO, 2000).

O impacto da expansão do núcleo industrial capitalista sobre as estruturas dependentes variou de região para região, sempre de acordo com as circunstâncias locais. Não obstante, o resultado se mostrava invariavelmente o mesmo: a criação de estruturas híbridas ou dualistas. Destarte, essa estrutura constitui especificamente o fenômeno do subdesenvolvimento, que tem como característica a existência de uma deformação estrutural substanciada no dualismo atrasado-moderno, isto é, na conformação de uma relação próxima da periferia com centro em termos geográficos, mas distante no que se refere a níveis tecnológicos e produtivos.

Diante disso, o conceito de centro-periferia está implicitamente ligado à ideia de desenvolvimento desigual. Os centros se identificam como as economias originárias das técnicas capitalistas, núcleos irradiadores de processos de produção (FURTADO, 2000). A periferia, por sua vez, é constituída por economias cuja produção permanece inicialmente atrasada pela ótica tecnológica e organizacional (RODRÍGUEZ, 2009). Entretanto, as regiões periféricas só absorvem o progresso técnico nos setores específicos ligados à produção de alimentos e matérias primas direcionadas aos grandes centros industriais, conformando assim, uma estrutura heterogênea.

\subsection{HETEROGENEIDADE ESTRUTURAL}

O conceito de heterogeneidade estrutural procura interpretar os desequilíbrios internos do subdesenvolvimento a partir das suas peculiaridades históricas e estruturais. Na concepção de heterogeneidade estrutural, os países em desenvolvimento apresentam, em sua maioria, disparidades entre setores e regiões as quais se referem ao grau de modernidade ou atraso, mas também à capacidade de gerar transbordamentos positivos, densidades tecnológicas e produtividades internas para seu entorno. Pinto (2000[1970]), ao definir heterogeneidade, salienta que o conceito pode ser entendido a partir da decomposição da economia em três "camadas básicas": (i) a camada "primitiva" que contempla a produção para a subsistência, com níveis de produtividade e renda per capita que se assemelham aos da economia colonial; (ii) a camada "moderna" composta pelas atividades de exportação, industriais e de serviços, com alta de 
produtividade, semelhantes às médias das economias desenvolvidas; e (iii) a camada “intermediária”, ou seja, entre os extremos, com nível de produtividade correspondente à média do sistema nacional.

Considerando a experiência das economias centrais com relação ao processo de homogeneização, este não se apresentou da mesma forma na periferia latino-americana. As causas disso seriam as seguintes: (i) o ritmo do desenvolvimento não engrenou, estando longe de se consolidar e se tornar autossustentado; (ii) a dependência metamorfoseou-se, porém ainda continuou presente (endividamento crônico, alienação das decisões da política econômica, subordinação tecnológica, etc.); (iii) grande parte da população, da estrutura produtiva e do espaço econômico foi marginalizada do avanço encontrado no polo moderno; e (iv) por fim, não se encontrava nenhum vestígio de que a situação anterior - a de heterogeneidade estrutural - viesse a se corrigir ou modificar.

\subsection{DESENVOLVIMENTO "HACIA AFUERA" E "HACIA ADENTRO"}

A partir da categoria centro-periferia, podemos encontrar o conceito de "desenvolvimento para fora", segundo o qual os métodos indiretos de produção gerados pelos centros industriais se difundem com relativo atraso nas periferias. Isto faz com se reproduza uma estrutura heterogênea, híbrida, na relação complexa entre o arcaico e o moderno. Essa diferenciação estrutural acompanha as regras das pautas tradicionais da divisão internacional do trabalho, como pontua Rodríguez (2009). A estrutura da periferia formada mediante o desenvolvimento para fora se mostrou com dois traços fundamentais: (i) uma parte da estrutura é especializada e voltada para a ampliação do setor exportador de produtos primários; e (ii) a demanda de bens e serviços diversificados é satisfeita através das importações (RODRIGUEZ, 2009).

Tavares (2000[1964]) descreve as principais características do modelo tradicional de desenvolvimento para fora. Nesse modelo, de acordo com a autora, é comum acentuar-se o alto peso relativo do setor externo para as economias primário-exportadoras dando ênfase ao papel desempenhado por duas variáveis básicas: (i) as exportações como variável exógena responsável pela geração de importante parcela da renda nacional e pelo seu crescimento; e (ii) as importações como fonte flexível de suprimento dos vários tipos de bens e serviços que atendem à demanda interna. Na verdade, na economia é importante entender a sinergia entre os papéis que as exportações desempenham em cada um dos casos (centro e periferia).

A trajetória da mudança do desenvolvimento para fora na direção do desenvolvimento para dentro esteve inicialmente vinculada a acontecimentos alheios aos limites nacionais das economias periféricas, ou seja, ocorreu devido a transformações ou movi- 
mentos cíclicos ocorridos na economia mundial. Sendo assim, surgem condições promissoras para o incentivo à produção interna de manufaturas, substituindo as que antes eram importadas, para se atender a uma demanda ociosa que não poderia ser mais satisfeita pelas importações devido às consequências dos estrangulamentos externos.

Então, como forma de superar os percalços trazidos pelos períodos cíclicos da economia mundial, segundo a visão de Furtado (1983), o que se propunha como desenvolvimento para dentro era um modelo de desenvolvimento pela via industrial. A partir dessa perspectiva, foram gestadas as ideias que vieram a servir de base ao desenvolvimento de políticas públicas nacionais dos países da América Latina, indicando claramente que o caminho dessas políticas seria a industrialização com intervenção do Estado, a partir da implementação do processo de substituição de importações, e cujo resultado seria a superação da condição subdesenvolvida desses países.

\subsection{CARACTERIZAÇÃO DO (SUB)DESENVOLVIMENTO PERIFÉRICO}

Celso Furtado "foi o intelectual mais dedicado a cobrir a análise cepalina com legitimação histórica. Dedicou-se à tarefa não só como historiador, mas também como teórico do subdesenvolvimento" (BIELSCHOWSKY, 2000, p. 22). A sua contribuição teve como função intencional defender a importância de entender o subdesenvolvimento como um processo histórico específico, exigindo uma teorização própria. A grande preocupação do desenvolvimento estruturalista era suprir a incapacidade dos modelos de crescimento de captar holisticamente as transformações das estruturas econômicas.

Para Furtado, estudar de forma integral o desenvolvimento exige analisar as complexas relações entre os sistemas econômicos nacionais de forma diacrônica. O ponto de partida da análise do subdesenvolvimento é o comportamento das áreas que assimilaram como por enxerto as técnicas forâneas voltadas para o processo produtivo, impulsionado pela expansão da economia industrial. Para Furtado (1992, p. 13),

[...] o subdesenvolvimento é uma variante do desenvolvimento, melhor, é uma das formas que historicamente assumiu a difusão do progresso técnico. O fato de que as estruturas que o conformam se hajam reproduzido no correr de decênios não nos autoriza a prever sua permanência futura. Mas podemos afirmar que a tendência dominante é no sentido dessa reprodução.

A teoria organizada por Furtado esquematiza a divisão do mundo em dois sistemas econômicos integrados pelo intercâmbio comercial, porém distantes por diferenças estruturais gritantes. Para o autor, o fenômeno de desenvolvimento compreende a ideia de crescimento, estendendo-a, de modo que se refere ao crescimento 
de um conjunto de estrutura complexa; porém, essa complexidade estrutural é uma questão de nível tecnológico, mas também traduz a diversidade das formas sociais e econômicas engendrada pela divisão social do trabalho. Na visão do autor, o subdesenvolvimento se traduz simultaneamente como um problema de acumulação e progresso técnico e como um problema de expressão dos valores de uma coletividade (FURTADO, 1983).

Furtado delimita como marco histórico a Revolução Industrial desencadeada no século XVIII, pois o entendimento do subdesenvolvimento requer uma análise do processo histórico de como ocorreram a difusão e o aprofundamento do capitalismo industrial no mundo. A Revolução Industrial ocasionou uma ruptura brusca no modus operandi da produção, que criou num segundo momento, um complexo sistema de divisão internacional do trabalho, integrando e transformando as economias nacionais em parte de um sistema global. Por conseguinte, ao se analisar a forma progressiva e peculiar de como se deu a difusão do capitalismo industrial no mundo, torna-se mais fácil entender a coexistência de países desenvolvidos e subdesenvolvidos. Nessa perspectiva, é importante estudar o mecanismo que faz com que a condição de subdesenvolvimento se perpetue e se reproduza. O estudo do subdesenvolvimento nos países periféricos se inicia com a análise exógena da expansão industrial europeia do século XVIII e se prolonga na análise endógena de como essas sociedades receberam essa estrutura e reagiram a essa penetração. Assim, o importante é compreender que surgiu um novo sistema de organização de produção que dera bastante importância ao custo do que se produzia. Essa política de redução de custos induziu a progressivos aperfeiçoamentos das técnicas de produção, abrindo um caminho interminável de possibilidades.

A transição da economia comercial para a industrial trouxe consigo mudanças profundas no sistema econômico. A economia industrial, por meio de métodos produtivos mais eficientes, se tornou cada vez mais capitalística, intensificando mais e mais o uso de equipamentos e outras formas de capital. Observa-se que a economia industrial não precisava de uma expansão das fronteiras geográficas para se desenvolver, pois o desenvolvimento se torna algo imanente ao sistema econômico industrial e se processa dentro de sua própria estrutura produtiva. $\mathrm{O}$ núcleo industrial europeu do século XVIII promoveu uma transformação profunda na economia mundial a partir do momento que passou a impulsionar o desenvolvimento em quase todas as regiões da terra. Esse núcleo dinâmico industrial se expandiu em várias direções.

Em termos analíticos, a condição de subdesenvolvimento ou desenvolvimento retardado, como queira chamar, considerando uma economia de forma isolada, corresponde em termos econômicos a um desequilíbrio no nível dos fatores de produção: capital e mão de obra. Esse desequilíbrio se fundamenta, na maioria das vezes, na es- 
cassez do fator capital e no excesso do fator trabalho. ${ }^{3}$ Pelo ângulo tradicional, as teorias do desenvolvimento são esquemas que explicam os processos sociais em que a assimilação de novas técnicas resulta no aumento da produtividade, que conduz à melhoria contínua do bem-estar de uma população que tende a se homogeneizar socialmente. Todavia, a teoria do subdesenvolvimento cuida do caso peculiar, no qual o aumento da produtividade e a assimilação de novas técnicas não conduzem à homogeneização social, mesmo que haja o aumento da renda média da população.

\subsection{MODERNIZAÇÃO E DEPENDÊNCIA}

Segundo Furtado (1983), pode-se considerar a modernização como um ponto central da problemática do subdesenvolvimento, pois seria uma das formas que assume o fenômeno da dependência. É o processo de adoção de padrões de consumo sofisticados, sem ter, em contrapartida, um padrão de acumulação de capital e métodos produtivos avançados correspondentes à demanda existente de bens finais. Quanto mais intenso é o processo de modernização dos padrões de consumo, mais intensa é a pressão que se faz na tentativa de ampliar o excedente, de modo que um país subdesenvolvido não pode de forma generalizada reproduzir o padrão de vida de uma sociedade mais avançada, em termos tecnológicos e produtivos materiais. A insistência na reprodução de padrões mais sofisticados na periferia se traduz na marginalização de grande parte da população dos privilégios do progresso.

Logo, o processo de difusão de novas técnicas deu-se, em certas áreas, quase exclusivamente pela introdução de novos produtos. Os processos produtivos permaneciam, no essencial, nos padrões tradicionais, sem nenhuma modificação. Chama-se de modernização essa forma de assimilação do progresso técnico quase exclusivamente no plano do estilo de vida, com fraca contrapartida no que diz respeito ao sistema de produção (FURTADO, 1992). Na visão do autor, confundir modernização com desenvolvimento se torna um erro, pois a modernização, na verdade, só agrava a concentração de renda e deixa mais explícita a estratificação social. Portanto, para que exista um desenvolvimento legítimo é necessário que o excedente produzido nos aumentos de produtividade seja canalizado para a poupança e invertido em atividades criadoras de emprego.

\footnotetext{
3 Um bom exemplo seriam as economias latino-americanas e o processo de modernização no processo produtivo ligado ao setor agrário exportador. Raúl Prebisch discute essa assimetria em seu texto "Problemas teóricos e práticos do crescimento econômico" (PREBISCH, 2000[1952]).
} 
Nas economias subdesenvolvidas em fase mais avançada de industrialização, as grandes empresas internacionais desempenham o papel de elemento dinamizador, constituindo a correia de transmissão dos novos produtos sem os quais não se diversificaria o consumo dos grupos dominantes. O acesso à constelação de produtos e processos originados no exterior implica o desenvolvimento dependente, o qual cria o estreitamento de vínculos com as grandes empresas transnacionais. Essas empresas, por sua vez, engendram a necessidade desses produtos e mantêm o controle das técnicas requeridas para produzi-los, desnudando o fenômeno da dependência (FURTADO, 1983).

\subsubsection{A INDUSTRIALIZAÇÃO NA TRANSFORMAÇÃO DAS ESTRUTURAS PERIFÉRICAS}

A industrialização periférica, em termos analíticos, foi composta basicamente por duas fases. A primeira pode ser considerada com um subproduto da expansão do modelo primário-exportador - principal condicionante de geração de renda nacional naquele período; a segunda fase, por sua vez, resultou das reações internas causadas pelo movimento recessivo da economia internacional durante a crise de 1929, conhecida como o processo de substituição de importações.

Nos países que se especializaram na exportação de produtos primários, a evolução das estruturas produtivas apresentou características singulares. Ao analisar a elevação da produtividade e do poder de compra da população, observou-se que estes provocaram modificações no perfil da demanda global no tocante a sua diversificação, desencadeando um aumento mais do que proporcional da procura de produtos manufaturados. Dessa forma, mesmo que a quantidade consumida de produtos manufaturados permaneça inalterada a partir de certos níveis de renda, não se pode dizer o mesmo com relação à sua qualidade. Além disso, com o progresso técnico, tanto as atividades primárias quanto as terciárias tendem a absorver quantidades crescentes de insumos industriais. Seguindo esse raciocínio, toda a elevação do poder de compra de dada população significa não apenas uma diversificação da procura, mas também uma diversificação mais do que proporcional da oferta de manufaturas. Todavia, a especialização na exportação de produtos primários, invariavelmente, concentra os fatores em poucas linhas de produção - um ou dois produtos apenas. Nota-se, então, que a estrutura produtiva periférica evolui de maneira inversa à que ocorre no perfil de sua demanda. Sendo assim, Furtado (2007, p. 174) salienta que, "observando o processo em seu conjunto, constata-se que a elevação de produtividade é acompanhada de uma simplificação na estrutura da oferta de origem interna e de diversificação na composição da demanda global”. 
O processo descrito acima constitui nos países latino-americanos o ponto de partida de sua industrialização tardia. A especialização produtiva permitiu a elevação da produtividade e da renda, engendrando um núcleo de mercado interno de produtos manufaturados, bem como a criação de uma infraestrutura. Por outro lado, enquanto na experiência clássica a industrialização resultou da introdução de inovações nos processos produtivos, condicionando a redução dos preços, e com a pressão competitiva permitiu a substituição dos produtos artesanais e a criação de um novo mercado, no caso latino-americano o processo não se deu da mesma forma, e o mercado formou-se como resultado da crescente produtividade causada pela especialização externa, sendo abastecido essencialmente mediante importações. É valido ressaltar que, na situação vista no segundo caso - o latino-americano -, na hipótese de industrialização regional, a concorrência não seria com os produtores artesanais de baixa produtividade - como no caso clássico -, mas sim com os produtores de elevada eficiência industrial presentes nos mercados mundiais.

A capacidade do embrionário mercado interno, necessário para a promoção da industrialização, dependia sem dúvida de uma série de circunstâncias que podiam variar de país para país. Em síntese, a transição para a economia industrial, dependeu, segundo Furtado (2007), de cinco fatores: (i) a natureza da atividade exportadora, da qual depende a quantidade relativa de mão de obra a ser absorvida; (ii) o tipo de infraestrutura exigido pela atividade exportadora; (iii) a propriedade dos investimentos, se estrangeira ou não; (iv) a taxa de salário que prevalece no setor exportador, condizente com as dimensões relativas do excedente de mão de obra; e (v) a dimensão absoluta do setor exportador, que reflete na maioria dos casos as dimensões geográfica e demográfica do país.

Para Furtado (2007, p. 184) o ponto de inflexão trazido pela crise de 1929 diz respeito à natureza do processo de industrialização, salientando que

até então, o desenvolvimento do setor industrial fora um reflexo da expansão das exportações; a partir desse momento, a industrialização seria principalmente induzida pelas tensões estruturais provocadas pelo declínio, ou crescimento insuficiente, do setor exportador.

Em conformidade com o nível de diversidade industrial encontrada em cada país, a contração do setor externo mostrou duas reações distintas: o retorno de fatores de produção ao setor pré-capitalista - agricultura de subsistência e artesanato; ou a expansão do setor industrial ligado ao mercado interno, num esforço de substituição total ou parcial dos bens que anteriormente eram importados. Dessa forma, a redução do coeficiente de importações se tornou possível graças a um crescimento mais do que 
proporcional do setor industrial, visto claramente no crescimento do coeficiente de industrialização entre os anos 1929 e 1957. O processo de industrialização evidenciado nos anos analisados dependeu também da ação estatal, por meio da concentração de investimentos em setores básicos, da recuperação e amparo do setor exportador e da introdução de capitais e tecnologia (FURTADO, 2007).

A explanação feita por Furtado deixa claro que a diferenciação estrutural obtida pela industrialização substitutiva de importações é um fator necessário para se superar o subdesenvolvimento, contudo não é suficiente. Entram aí, como descrito na subseção anterior, outros fatores ligados à inserção das economias no sistema econômico internacional que "limitam" esse processo, fatores esses característicos da relação entre os centros e as periferias, conformando situações específicas de dependência e modernização (FURTADO, 1983). Essa primeira seção teve o intuito principal servir de apoio teórico para se analisar os fatos que serão vistos nas próximas seções.

\section{AMÉRICA LATINA E A REESTRUTURAÇÃO PRODUTIVA A PARTIR DA DÉCADA DE 1990: PARA ONDE VAMOS}

Há duas características nas economias latino-americanas que as distingue das economias desenvolvidas: uma delas relaciona-se ao atraso relativo entre as capacidades tecnológicas comparadas à fronteira internacional; a outra tem a ver com a diferença de produtividade existente entre setores e dentro de cada um deles. Nos trabalhos pioneiros da moderna teoria do desenvolvimento, tendo como principais autores C. Furtado (1983[1967]), R. Prebisch (2000a[1949]), R. Nurske (1953) e A Lewis (1954), entre outros, salientava-se a importância da estrutura produtiva e de sua transformação como determinantes da transição de economias tradicionais para economias mais avançadas. Assim, considerando um processo virtuoso as economias deveriam se diversificar para setores com maior conteúdo tecnológico. Em muitos países desenvolvidos esse processo é tido como natural, no qual os trabalhadores da agricultura passam para a indústria e posteriormente transferem-se para os serviços. Assim, a participação da indústria no emprego total deveria apresentar uma curva invertida com formato de "U”. No entanto, sustentar esse argumento nos leva a uma simplificação que oculta várias especificidades da região que são fundamentais para o seu desenvolvimento. Como frisado por CEPAL (2010) essa transição não é unívoca e pode conduzir às economias a "becos sem saída", produto de uma especialização regressiva.

Atualmente continua sendo um desafio a modificação da estrutura produtiva e a redução da heterogeneidade estrutural. Um obstáculo a essa modificação se manifesta na dificuldade da mudança dos setores de baixa produtividade para setores de 
alta produtividade. Esse processo de transformação, grosso modo, é denominado de mudança estrutural, um caminho percorrido pela maioria dos países desenvolvidos. No percurso dos países desenvolvidos existe um denominador comum que é a inovação, que se apresenta como motor do crescimento e do desenvolvimento. Nesse sentido, Schumpeter (1982) veio contribuir de forma importante para interpretar as mudanças na economia desencadeadas pela inovação, definida pelo autor como novos produtos, novos processos e novas mudanças organizacionais que abram possiblidades de investimento que conduzem a uma mudança das estruturas produtivas. Assim, para esse autor a inovação gera ciclos de expansão a partir de clusters que impactariam positivamente o investimento e a demanda efetiva. Entretanto, Schumpeter na obra "Socialismo, capitalismo e democracia" (1961[1952]) salienta como ponto importante para o desenvolvimento o processo no qual se destroem as estruturas produtivas existentes e se criam outras novas regenerando o sistema econômico. Em outras palavras, para o autor a dinâmica do sistema econômico é movida pelo processo de "destruição criadora", o qual faz desaparecer setores para surgirem outros modificando a estrutura produtiva.

No entanto, para os países em desenvolvimento muitas vezes esse processo se apresenta como uma trajetória contraditória: ao invés de absorver a baixa produtividade para transformá-la em alta produtividade, os setores perpetuam a estrutura atrasada como um círculo vicioso, como referenciávamos na primeira seção deste artigo. Um dos grandes problemas assinalados pela CEPAL e seus autores corresponde às dificuldades da região de absorver progresso técnico. Nesse caso, como salientava Prebisch (2000b[1952]), a região apresenta estrutura caracterizada como centro-periferia com assimetria entre as estruturas produtivas. Existem diferenças no interior do sistema produtivo no qual grande parte da força de trabalho é absorvida por setores de baixa produtividade. Essa assimetria entre os setores produtivos se transforma em diferentes elasticidades-renda da demanda por exportações e importações, afetando a balança comercial e a vulnerabilidade externa.

Como assinalam Porcile e Martins (2017), a demanda de bens com maior conteúdo tecnológico tende a aumentar mais do que a demanda de commodities, sendo este o fato definidor de uma inserção internacional muito mais dinâmica para aqueles países que exportam bens tecnológicos. Quando a periferia vivencia um ciclo de expansão, tende a importar mais bens tecnológicos do que aumentam suas exportações quando cresce a economia mundial. Dessa forma, pode se dizer que a região tem restrições externas que estão relacionadas com a estrutura produtiva.

Para superar a vulnerabilidade e a elasticidade da demanda deve-se transformar a estrutura produtiva - ponto fulcral da teoria cepalina - e, para levar a frente esse objetivo a periferia deve absorver as novas tecnologias muito rapidamente. No entanto, 
essa transformação é uma trajetória que parece invertida no setor da indústria nas últimas décadas. Assim, para exemplificar esse ponto, na continuação apresentaremos alguns dados estilizados para entender a evolução dinâmica da região.

\subsection{CONTEXTUALIZAÇÃO DO PERÍODO EM ANÁLISE: FATOS ESTILIZADOS}

A década de 1990 marcou o triunfo das ideias neoliberais concretizadas na adoção dos pressupostos do Consenso de Washington. Os modelos denominados de ajuste estrutural visavam erradicar a instabilidade da região priorizando a luta contra a inflação, a disciplina fiscal e o controle monetário. As medidas aplicadas tiveram sucesso em debelar a inflação, corrigindo o nível de preços e o funcionamento dos mercados. Nesse período a região experimentou grandes flutuações que podem ser explicadas tanto pelas mudanças estruturantes quanto pelas variações de entrada e saída de capitais financeiros externos. Os resultados em termos de crescimento foram medíocres na década de 1990, assim como no aspecto social, cujos indicadores aguçaram ainda mais sua tendência negativa.

$\mathrm{Na}$ década de 2000, a região voltou a discutir pontos centrais do desenvolvimento especificamente focando na necessidade de ter a igualdade como horizonte para a mudança estrutural. O período entre 2004-2008 foi marcado por uma recuperação guiada pela "bonança" vivenciada pela economia internacional, que afetou positivamente a balança comercial, puxada pelas exportações de commodities. A crise financeira que teve início em 2008 interrompeu o ciclo expansivo de crescimento, o qual acontecia num contexto de expansão da econômica internacional. Essa crise teve repercussão em todos os mercados financeiros, mas também nas variáveis reais das economias mundiais por meio da retração do crédito, da destruição de riqueza, da queda do comércio mundial e da deterioração das expectativas sobre a evolução da atividade econômica (CEPAL, 2010). Dessa forma, perfilou-se na economia mundial um novo cenário com taxas de crescimento menores, desaceleração do comércio, menor transnacionalização financeira e nova arquitetura financeira global.

Assim, podemos observar no Gráfico 1 o comportamento do PIB da região, o qual apresenta tendência de alta crescente de 2000 até 2008, ano da crise internacional, e a partir de então a economia não consegue retomar essa senda de crescimento, mostrando uma tendência decrescente na década de 2010.

Com relação ao investimento entendido como formação bruta de capital fixo (FBKF), um dos componentes da demanda agregada, a América Latina apresenta taxa de investimento que tem sido historicamente menor que as das outras regiões emergentes, em particular os países da Ásia. Essa última região tinha uma taxa de investi- 
mento de 27,8\% do PIB em 1980, passando a ser 35\% em meados de 1990, e sendo superior ao $40 \%$ atualmente. Esse fenômeno é um dos pontos da mudança na Ásia, que foi se transformando numa região muito mais dinâmica do que a América Latina (BIELCHOWSKY e TORRES, 2018).

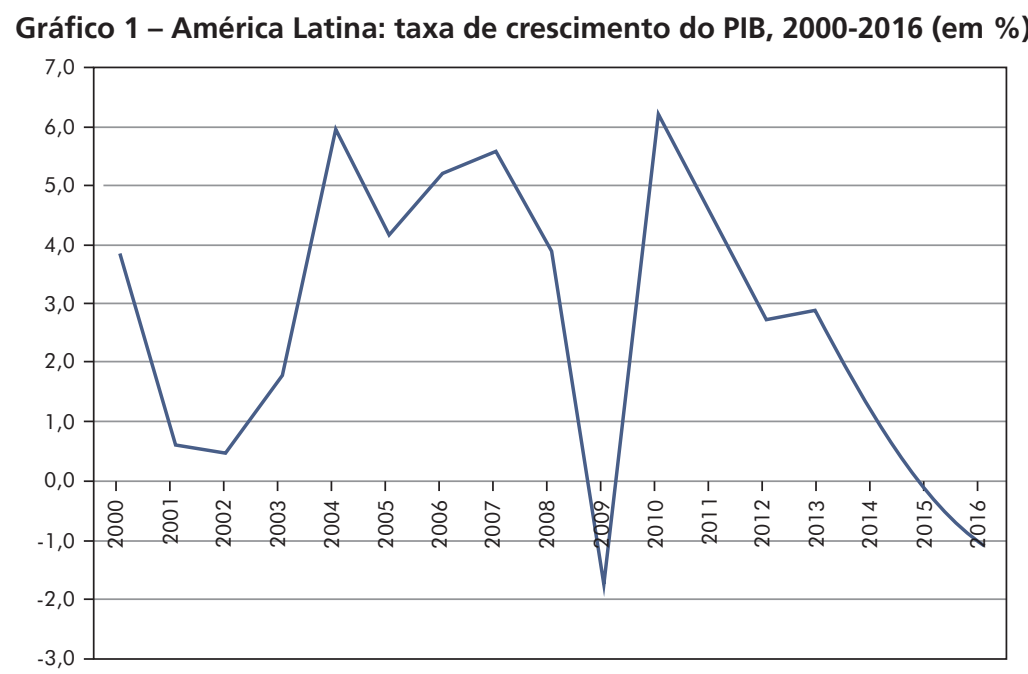

Fonte: Elaboração própria com base em dados da CEPAL (2019).

Tabela 1 - América Latina: composição da FBKF (em \% do PIB)

\begin{tabular}{lcccccc}
\hline INVESTIMENTO & $\mathbf{1 9 8 0 - 1 9 8 1}$ & $\mathbf{1 9 8 2 - 1 9 9 0}$ & $\mathbf{1 9 9 1 - 1 9 9 4}$ & $\mathbf{1 9 9 5 - 1 9 9 8}$ & $\mathbf{1 9 9 9 - 2 0 0 3}$ & $\mathbf{2 0 0 4 - 2 0 1 0}$ \\
\hline Investimento público & 6,7 & 5,2 & 4,7 & 4,4 & 3,9 & 4,8 \\
Investimento privado & 14,3 & 11,1 & 14,1 & 15,6 & 14,7 & 15,9 \\
\hline
\end{tabular}

Nota: Percentual calculado como média simples dos seguintes países: Argentina, Bolívia, Brasil, Chile, Colômbia, Peru, Equador, México, Paraguai, Uruguai, Venezuela.

Fonte: Elaboração própria com base em dados da CEPAL (2018).

A partir da Tabela 1, podemos observar o desempenho da FBKF com tendência decrescente, tanto no âmbito público quanto no privado. Com relação à inversão pública, sua tendência declinante torna-se preocupante fundamentalmente pelo impacto positivo que teria sobre o crescimento. Os investimentos privados apresentam variações entre países; no entanto, os principais países da região apresentaram queda, como por exemplo o Brasil, onde na década de 1980 o nível da taxa oscilava ao redor de $20 \%$ e passou a $16 \%$ em 2010; a Argentina, que apresentava 22,9\% em 1980 e passou a 18,6\% em 2010; o Chile, que tinha 16,6\% em 1980 aumentou para $23 \%$ sua taxa; e o México, que passou de $14,3 \%$ para 16,5\%. Assim, esses comportamentos na média 
acabaram compensando os efeitos negativos de alguns países, mas podemos dizer que não houve grandes mudanças com relação ao investimento.

Com relação ao setor externo e à inserção internacional da região na economia mundial, observamos que, em mais de 25 anos mostrados na série em análise no Gráfico 2, existiram mudanças na tendência do comportamento do comércio. Assim, explicitaremos a seguir os diferentes pontos: (i) na década de 1990 a tendência foi de queda do saldo comercial, que se tornou negativo a partir de 1993 em decorrência das políticas de abertura comercial implementadas na região; (ii) a partir do ano 2002 a tendência é de forte recuperação, com a curva modificando o sentido e tornando-se positiva, com saldos comerciais também positivos, frutos da recuperação da economia mundial e do aumento significativo da demanda das commodities latino-americanas, fundamentalmente as agrícolas e as minerais; e (iii) a partir de 2008, depois da crise do subprime, a economia mundial entra em um período de estancamento no crescimento, e mesmo a China encontra um novo "normal" com taxa de crescimento menor, fenômeno que afetou a demanda mundial de commodities e repercutiu negativamente na balança comercial, a qual apresentou então tendência de queda. Com relação às perspectivas de mudanças da tendência negativa, depois da crise de 2008 existe uma queda no ritmo de crescimento das exportações mundiais e do PIB mundial. Por outro lado, as exportações dos países em desenvolvimento para os países desenvolvidos diminuíram, como mostra a Tabela 2.

Gráfico 2 - América Latina: evolução do saldo da balança comercial, 1990-2016 (em USD milhões)

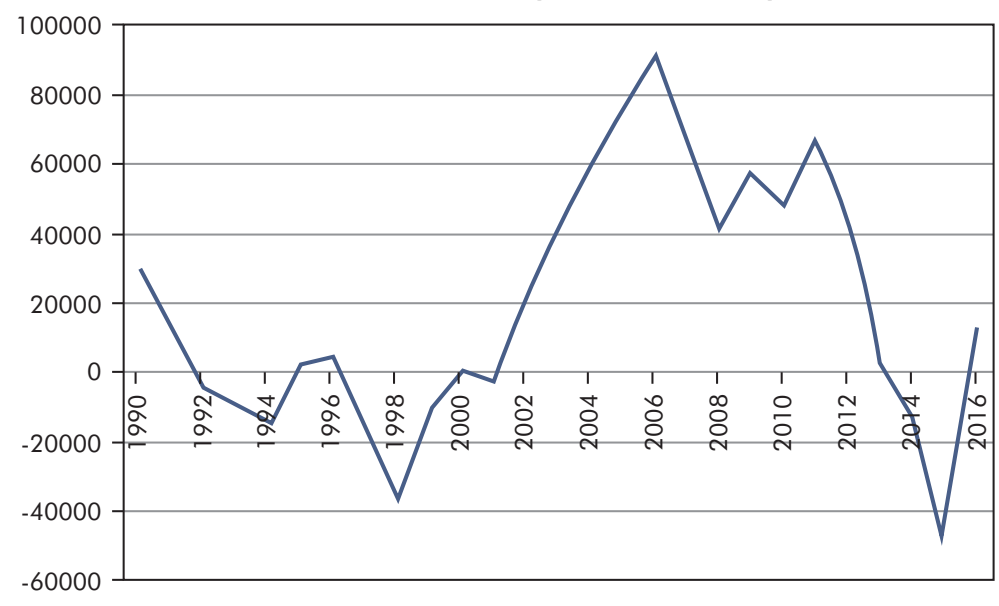

Fonte: Elaboração própria com base em dados da CEPAL (2019). 
Tabela 2 - Evolução do comércio mundial entre grandes regiões, 2010-2013 (em \%)

\begin{tabular}{lccccc}
\hline Ano & Norte-Norte & Norte-Sul & Sul-Sul & Sul-Norte & Mundo \\
\hline 2010 & 12,3 & 25,7 & 36,3 & 28,1 & 22,5 \\
2011 & 15,2 & 18,6 & 32,5 & 21,4 & 21,0 \\
2012 & $-4,6$ & 0,8 & 12,0 & 17,7 & 4,8 \\
2013 & 3,0 & 3,1 & 3,9 & $-0,4$ & 2,6 \\
\hline
\end{tabular}

Fonte: CEPAL (2014).

Assim, depois de mostrar alguns dados esclarecedores do rumo da região, passamos na continuação a analisar a estrutura produtiva e as possibilidades de mudança nas últimas décadas.

\subsection{AMÉRICA LATINA: DESEMPENHO DA ESTRUTURA PRODUTIVA}

Passaram-se já 70 anos dos primeiros escritos da CEPAL e o legado deixado pela instituição permanece atual. A transformação produtiva sempre foi um ponto que guiou os trabalhos, baseados na dinâmica tecnológica como forma de superar a estrutura atrasada e subdesenvolvida. Como salientamos na primeira seção, na década de 1950 a transformação da estrutura produtiva estava relacionada com a industrialização, que permitiria à região a mudança do setor dinâmico da agricultura para indústria. As teorias que surgem nesse momento correspondem ao período em que na região predominavam as estruturas dualistas. Atualmente, essa transformação é muito mais complexa, pois em nível mundial há estruturas variadas, com fragmentação da produção e o surgimento do setor de serviços intensivo em tecnologia. Esse é o contexto no qual o debate sobre mudança estrutural e especialização se transforma em um tema complexo. Nesse sentido, Porcile e Martins (2017) argumentam que atualmente o que se procura é uma maior competitividade, sendo que para consegui-la deve-se focar na análise da produtividade e da mudança tecnológica. Assim, os autores assinalam que para aumentar a produtividade deve-se diversificar a estrutura produtiva em direção a setores intensivos em tecnologia. Nos dizeres de Porcile e Martins (2017, p.67): "la periferia deve ser capaz de aprender, absorber e incorporar las nuevas tecnologias a una velocidade mayor que la velocidad com que os centros innovan". Entretanto, Prebisch defendia a ideia de que a estrutura produtiva tem um papel fundamental no desenvolvimento e na superação da tendência crônica que a região experimenta com relação aos desequilíbrios externos. Para que a mudança estrutural acontecesse, na visão de Prebisch, era necessário políticas tendentes a atrair acumulação de capital para atividades industriais, que permitem absorver os frutos do progresso tecnológico. 
Gráfico 3 - América Latina: participação dos grandes setores econômicos no PIB, anos selecionados (em \%)

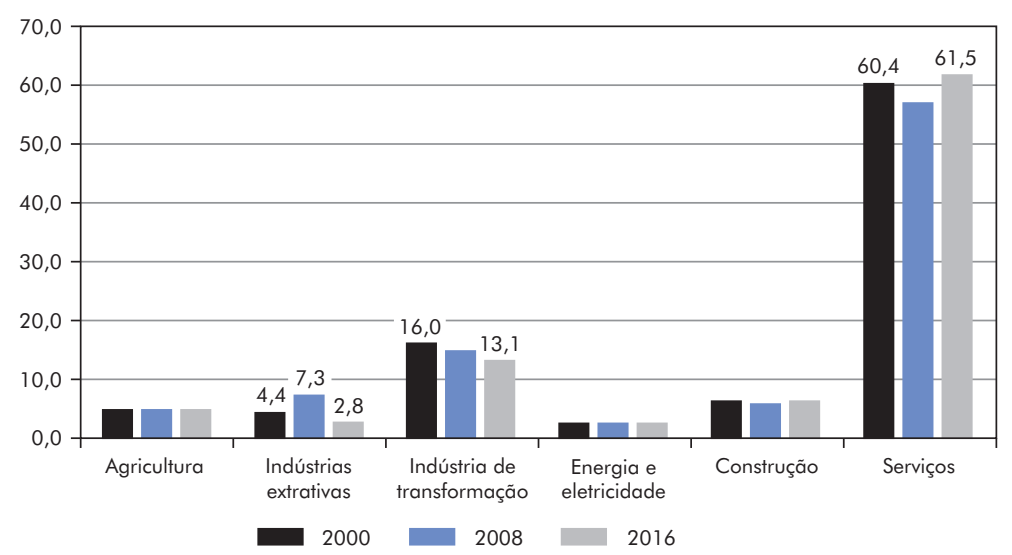

Fonte: Elaboração própria com base em dados de CEPAL (2019).

Assim, é importante analisar o comportamento da estrutura produtiva nos últimos anos para observar a contribuição no PIB na região e as possibilidades de desenvolvimento geradas. Como pode se observar no Gráfico 3, que analisa os grandes setores econômico na região em anos selecionados das últimas décadas, o setor industrial não apresenta mudanças, pelo contrário, o mesmo cai em participação do PIB de $16 \%$ para $13,1 \%$. Seguindo o pensamento da CEPAL, o caminho do desenvolvimento encontrar-se-ia na melhoria da competitividade e da produtividade; porém, o principal setor no qual esses fatores podem evoluir está perdendo protagonismo na região. Por outro lado, o setor que ganha participação é o das indústrias extrativas que duplica sua participação na década de 2000, mostrando como o auge dos commodities repercute na economia da região. Outro setor que apresenta dinamismo moderado é o dos serviços, que ganha impulso nos principais países, como por exemplo Brasil e Argentina.

Tabela 3 - América Latina: participação de setores econômicos no PIB e o emprego, 1980-2014 (em \%)

\begin{tabular}{lcccccccccc}
\hline \multirow{2}{*}{ SETORES } & \multicolumn{4}{c}{ Valor Agregado } & \multicolumn{5}{c}{ Emprego } \\
\cline { 2 - 12 } & $\mathbf{1 9 8 0}$ & $\mathbf{1 9 9 0}$ & $\mathbf{2 0 0 2}$ & $\mathbf{2 0 0 8}$ & $\mathbf{2 0 1 4}$ & $\mathbf{1 9 8 0}$ & $\mathbf{1 9 9 0}$ & $\mathbf{2 0 0 2}$ & $\mathbf{2 0 0 8}$ & $\mathbf{2 0 1 4}$ \\
\hline Agricultura & 4,9 & 5,2 & 5,5 & 5,4 & 5,1 & 23,2 & 18,6 & 19,1 & 17,3 & 15,0 \\
Mineração & 6,7 & 7,8 & 8,1 & 7,3 & 6,6 & 1,0 & 0,8 & 0,5 & 0,5 & 0,6 \\
Indústria de transformação & 20,0 & 17,8 & 16,6 & 16,3 & 14,7 & 16,4 & 18,2 & 14,3 & 14,0 & 12,7 \\
Energia & 1,6 & 2,2 & 2,7 & 2,6 & 2,6 & 0,9 & 0,9 & 0,5 & 0,5 & 0,5 \\
\hline
\end{tabular}


Tabela 3 - América Latina: participação de setores econômicos no PIB e o emprego, 1980-2014 (em \%)

\begin{tabular}{lcccccccccc}
\hline \multirow{2}{*}{ SETORES } & \multicolumn{4}{c}{ Valor Agregado } & \multicolumn{5}{c}{ Emprego } \\
\cline { 2 - 10 } & $\mathbf{1 9 8 0}$ & $\mathbf{1 9 9 0}$ & $\mathbf{2 0 0 2}$ & $\mathbf{2 0 0 8}$ & $\mathbf{2 0 1 4}$ & $\mathbf{1 9 8 0}$ & $\mathbf{1 9 9 0}$ & $\mathbf{2 0 0 2}$ & $\mathbf{2 0 0 8}$ & $\mathbf{2 0 1 4}$ \\
\hline Construção civil & 10,1 & 7,3 & 6,6 & 7,0 & 7,1 & 7,3 & 6,3 & 6,0 & 7,0 & 7,8 \\
Comércio & 15,4 & 13,7 & 13,6 & 14,6 & 14,6 & 13,9 & 18,5 & 23,3 & 23,4 & 24,1 \\
Transporte e comunicações & 4,2 & 4,9 & 6,7 & 7,2 & 9,2 & 4,7 & 5,0 & 5,2 & 5,8 & 6,2 \\
Serviços financeiros & 14,5 & 16,0 & 16,0 & 16,7 & 17,7 & 5,6 & 6,3 & 5,7 & 6,8 & 7,6 \\
Serviços comunitários & 22,6 & 25,1 & 24,2 & 23,0 & 22,4 & 27,1 & 25,5 & 25,3 & 24,8 & 25,3 \\
Total & $\mathbf{1 0 0}$ & $\mathbf{1 0 0}$ & $\mathbf{1 0 0}$ & $\mathbf{1 0 0}$ & $\mathbf{1 0 0}$ & $\mathbf{1 0 0}$ & $\mathbf{1 0 0}$ & $\mathbf{1 0 0}$ & $\mathbf{1 0 0}$ & $\mathbf{1 0 0}$ \\
\hline
\end{tabular}

Fonte: Elaboração própria com base em dados de CEPAL (2019).

Na visão de alguns autores, o caminho da evolução para uma economia de serviços é um processo normal do desenvolvimento na medida que eles estivessem atrelados ao setor industrial e aos ganhos de produtividade típicos de setores mais intensivos em tecnologia. No caso da América Latina, esse processo se dá mais sem ter o suporte da indústria pois ela vem perdendo dinamismo. Nesse sentido, alguns autores (OREIRO e FEIJÓ, 2010; ROWTHORN e RAMASWANY, 1999; TREGENNA, 2009) argumentam que países da região, como por exemplo o Brasil, vivenciaram um processo de desindustrialização. Existe um amplo debate sobre o tema da desindustrialização, cuja interpretação gera controvérsias, e não realizaremos aqui essa explicação pois escapa de nosso objetivo. No entanto, é importante salientar que, para Tregenna (2009), desindustrializar constitui uma situação na qual tanto o emprego industrial quanto o valor adicionado da indústria se reduzem como proporção do emprego total e do PIB. Assim, podemos observar na Tabela 3 como o nível de emprego se comporta nas últimas décadas. Observa-se uma queda no setor da indústria e um aumento no setor dos serviços, como por exemplo comércio e serviços financeiros. Isso mostra como a estrutura se modificou sem abranger questões fundamentais como o emprego - o qual, numa situação virtuosa do desenvolvimento, deveria aumentar ou migrar de setores de baixa produtividade para os de maior tecnologia.

Esse processo foi acompanhado da quase inexistência de políticas industriais ativas, corroborando o marco das políticas neoliberais pró-mercado, tendo como reflexo o pouco dinamismo do setor produtivo nas décadas em estudo. Isso fez com que não se criara um ambiente com capacidade tecnológica de aumentar a competitividade e a produtividade. As consequências dessa situação devem ser observadas na inserção externa e no avanço da produtividade. 
$\mathrm{Na}$ Tabela 4 apresentam-se os níveis de produtividade do trabalho de cada setor como porcentagem da produtividade média da economia. Podemos observar que as diferenças entre setores são muito gritantes: por exemplo, a produtividade do setor das extrativas minerais é sete vezes mais alta do que a produtividade média, enquanto a do setor de energia é quatro vezes maior do que a média, assim como a do setor financeiro é duas vezes superior à média. A indústria apresenta produtividade similar à média da economia. Observando a evolução da produtividade, houve ampliação da desigualdade entre 1990 e 2008. Isso vem ao encontro das dificuldades que a região apresenta no quesito de mudança estrutural, pois o setor da indústria não apresenta produtividade crescente; pelo contrário, ela permanece quase inalterada, enquanto as indústrias extrativas se mostram como as mais produtivas.

Tabela 4 - América Latina: índice de produtividade

\begin{tabular}{lcccc}
\hline SETORES & $\mathbf{1 9 9 0}$ & $\mathbf{1 9 9 8}$ & $\mathbf{2 0 0 3}$ & $\mathbf{2 0 0 8}$ \\
\hline Agricultura & 28,4 & 27,7 & 30,9 & 31 \\
Extrativas minerais & 608,4 & $1.045,50$ & 932,8 & 767,4 \\
Indústria & 99,3 & 112,7 & 115,5 & 114,2 \\
Energia & 225,9 & 353,6 & 434,6 & 483,2 \\
Construção & 91,3 & 94,4 & 84,7 & 77,5 \\
Comércio & 76,1 & 63,3 & 56,2 & 59,5 \\
Transporte & 118,7 & 134,4 & 148,4 & 146,1 \\
Serviços financeiros & 279 & 282,5 & 279,7 & 252,1 \\
PIB total & 100 & 100 & 100 & 100 \\
\hline
\end{tabular}

Fonte: Adaptado de Bielschowsky e Torres (2018).

Essa mudança que a economia apresenta pode ser relacionada com a ampliação da demanda internacional das indústrias extrativas a partir do aumento do comércio com a China. Isso denota que a região caminhou para uma especialização regressiva na medida em que o setor que apresenta maior dinamismo é o de commodities, com pouco valor agregado e incapaz de gerar os encadeamentos para frente e para trás, assim como também de gerar fomento tecnológico.

Nesse sentido, as ideias da CEPAL parecem pertinentes até hoje quando se analisa a mudança estrutural na região. Vai nesse sentido a tese levantada por Aníbal Pinto (2000[1970], p. 578), segundo a qual: "refinou essa análise com o argumento de que o processo de crescimento na América Latina estava tendendo a reproduzir de forma renovada a velha heterogeneidade estrutural prevalecente no período agrário-exportador”. A região mudou sua estrutura em função de uma forma de inserção internacional "periférica" sendo fornecedora de commodities na divisão internacional do trabalho. 
O Gráfico 4 mostra as exportações segundo a intensidade tecnológica, e nele podemos observar que a participação mais representativa é a dos produtos primários e da manufatura de baixa tecnologia. O setor de recursos naturais também se mostra significativo e junto com setor de produtos primários representa $50 \%$ do total das exportações. Essa tendência foi construída na década de 2000 e se mantém na década seguinte.

\section{Gráfico 4 - América Latina: exportações para o mundo segundo grau de tecnologia, 2014 (em \%)}

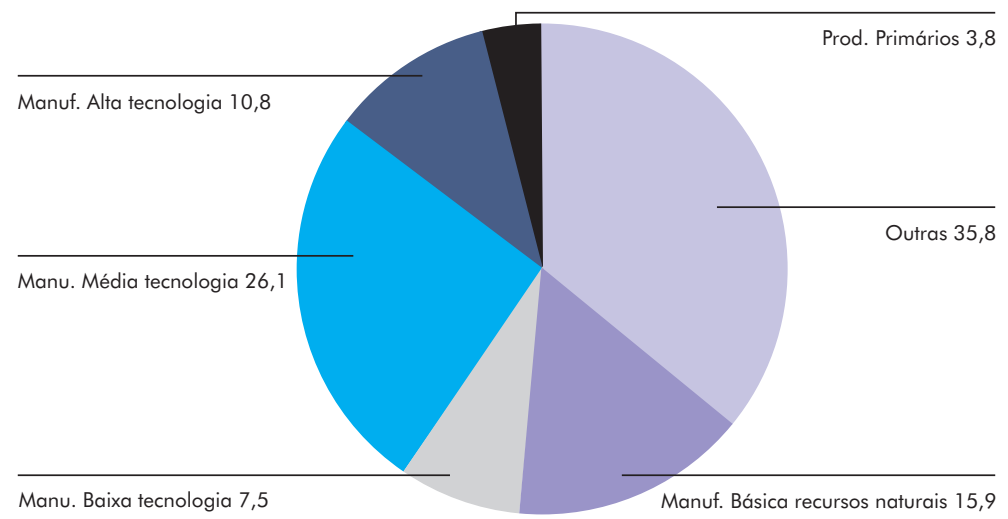

Fonte: Elaboração própria com base em dados de The World Bank (2018).

Diante do paradoxo vivido pela região, fica a dúvida sobre as reais possibilidades de aceleração do desenvolvimento ou de torná-lo autossustentado. Como Pinto (2000[1970], p. 575) frisara: "mais do que um progresso para a homogeneização da estrutura global, perfila-se um aprofundamento da heterogeneidade". Nesse sentido, a região ainda tem muitos desafios pela frente.

\section{CONSIDERAÇÕES FINAIS}

A mudança estrutural redefine as relações entre crescimento, produtividade e emprego, assim como o valor agregado de cada setor no PIB. Nas contribuições teóricas da CEPAL na década de 1950, a mudança estrutural se configurava como o motor do desenvolvimento quando se focava em superar a estrutura dualista. $\mathrm{O}$ desempenho econômico atual da região leva a se questionar como se "perfila" a mudança estrutural, porque ela se apresenta dependendo de fatores externos: contexto internacional puxado pela demanda chinesa de matérias primas e produtos de alta intensidade de recursos naturais. 
A conclusão a que se chega, de modo geral, é a de que o setor industrial na região não avançou durante os anos 2000. As informações desse período corroboram uma constatação preocupante, a de que, a despeito de todas as mudanças de modelos econômicos implementados, a América Latina parece ter se afastado um pouco mais do mundo desenvolvido do que dele se aproximado. A mudança estrutural experimentada pela região a levou para uma relativa especialização, fenômeno que não seria grave se ocorresse no sentindo dos setores de maior conteúdo tecnológico, em vez dos setores produtores de commodities.

O desafio da absorção de tecnologia é um ponto urgente da agenda de desenvolvimento e continua sendo um fator chave. As teses cepalinas, como heterogeneidade estrutural, inserção externa e as relações centro-periferia, continuam atuais só que com um renovado contexto histórico, que coloca a necessidade de repensar os pontos centrais do desenvolvimento. $\mathrm{O}$ auge dos commodities que permitiu à região experimentar um ciclo de expansão não foi acompanhado de uma visão estratégica com relação à tecnologia e à inovação como fatores fundamentais do desenvolvimento. Pelo contrário, em geral os modelos de ajuste estrutural inspirados no ideário liberal deixaram as políticas pró-mercado agir e com isso o papel do Estado foi menor na direção do desenvolvimento.

A América Latina deve enfrentar o desafio da mudança estrutural, mas de uma forma virtuosa. Na verdade, ela acontece de uma forma complexa e requer a análise de muitas variáveis que entrariam na construção, como, por exemplo, políticas industriais, de ciência e tecnologia, investimentos em CT\&I, papel do Estado, etc. Por outro lado, não se deveria esquecer o legado deixado pela CEPAL, que foi o da diversificação industrial e da integração das cadeias produtivas. Este deveria ser o ponto de partida para uma nova agenda de desenvolvimento da região.

\section{REFERÊNCIAS}

BIELSCHOWSKY, R. "Introdução". In: BIELSCHOWSKY, R. (Org.). Cinquenta anos de pensamento na CEPAL. Rio de Janeiro, São Paulo: Editora Record, 2000. Vol. 1.

BIELSCHOWSKY, R.; TORRES, M. (Orgs.). Desarrollo e igualdad: el pensamiento de la CEPAL en su séptimo decenio. (Colección 70 años, n. 1) Santiago de Chile: CEPAL, 2018.

CEPAL - COMISSÃO ECONÔMICA PARA AMÉRICA LATINA. A hora da igualdade: brechas por fechar, caminhos por abrir. Trigésimo terceiro período de sessões da CEPAL, Brasília, 30 de maio a $1^{\circ}$ de junho de 2010. Santiago de Chile: CEPAL, 2010.

CEPAL - COMISSÃO ECONÔMICA PARA AMÉRICA LATINA. Panorama de la inserción internacional de América Latina y el Caribe. Integración regional y cadenas de valor en un escenario externo desafiante. Santiago de Chile: CEPAL, 2014. 
CEPAL - COMISSÃO ECONÔMICA PARA AMÉRICA LATINA. Anuário Estatístico de América Latina y el Caribe. Santiago de Chile: CEPAL, Vários Anos.

CEPAL - COMISSÃO ECONÔMICA PARA AMÉRICA LATINA. CEPALSTAT. Bases de datos y publicaciones estadisticas. Santiago de Chile: CEPAL, mar.2019.

FURTADO, C. Teoria e política do desenvolvimento econômico. (Coleção Os Economistas). São Paulo: Abril Cultural, 1983[1967].

FURTADO, C. O subdesenvolvimento revisitado. Economia e Sociedade, v. 1, n. 1, p. 5-19, 1992.

FURTADO, C. Introdução ao desenvolvimento: enfoque histórico-estrutural. Rio de Janeiro: Paz e Terra, 2000.

FURTADO, C. A economia latino-americana: formação histórica e problemas contemporâneos. 4. ed. São Paulo: Companhia das Letras, 2007.

LEWIS, A. O "Desenvolvimento econômico com oferta ilimitada de mão-de-obra". In: AGARWALA, A. N.; SNIGH, S.P. (Eds.) A economia do subdesenvolvimento. Rio de Janeiro: Forense, 1969[1954].

NURKSE, R. "Alguns aspectos internacionais do desenvolvimento econômico". In: AGARWALA, A. N.; SNIGH, S. P. (Eds.) A economia do subdesenvolvimento. Rio de Janeiro: Forense, 1969[1952].

OREIRO, J. L.; FEIJÓ, C. A. Desindustrialização: conceituação, causas, efeitos e o caso brasileiro. Revista de Economia Política, v. 30, n. 2, abr./jun 2010.

PINTO, A. "Natureza e implicações da 'heterogeneidade estrutural' da América Latina”. In: BIELSCHOWSKY, R. (Org.). Cinquenta anos de pensamento na CEPAL. Rio de Janeiro, São Paulo: Editora Record, 2000[1970], Vol. 2, p. 567-588.

PORCILE, G.; MARTINS, A. “Cambio estructural, crecimiento y política industrial”. In: CEPAL - COMISSÃO ECONÔMICA PARA AMÉRICA LATINA. Políticas Industriales y tecnológicas en América Latina. Santiago de Chile: CEPAL, 2017, p. 61-76.

PREBISCH, R. "O desenvolvimento econômico da América Latina e alguns de seus problemas principais". In: BIELSCHOWSKY, R. (Org.). Cinquenta anos de pensamento na CEPAL. Rio de Janeiro, São Paulo: Editora Record, 2000a[1949], Vol. 1, p. 69-136

PREBISCH, R. "Problemas teóricos e práticos do crescimento econômico”. In: BIELSCHOWSKY, R. (Org.). Cinquenta anos de pensamento na CEPAL. Rio de Janeiro, São Paulo: Editora Record, 2000b[1952], Vol. 1, p. 179-215

RODRÍGUEZ, O. O estruturalismo latino-americano. Rio de Janeiro: Civilização Brasileira, 2009.

ROWTHORN, R.; RAMASWANY, R. Growth, trade and deindustrialization. IMF Staff Papers, v. 46, n.1, 1999.

SCHUMPETER, J. A. Teoria do desenvolvimento econômico. São Paulo: Abril Cultural, 1982.

SCHUMPETER, J. A. Socialismo, capitalismo e democracia. Rio de Janeiro: Editora Fundo de Cultura, 1961[1952].

TAVARES, M. C. “Auge e declínio do processo de substituição de importações no Brasil”. In: BIELSCHOWSKY, R. (Org.). Cinquenta anos de pensamento na CEPAL. Rio de Janeiro, São Paulo: Editora Record, 2000[1964], Vol. 1, p. 217-237 
TREGENNA, F. Characterizing deindustrialization: an analysis of changes in manufacturing employment and output internationally. Cambridge Journal of Economics, v. 33, n. 3, p. 433466, May 2009.

THE WORLD BANK. The World Bank Indicators. [On-line] The World Bank, 2018. Disponível em: <https://data.worldbank.org/indicator>. 